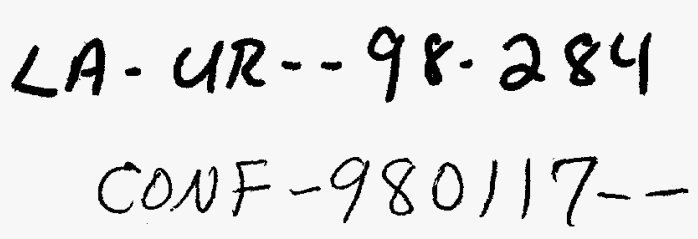

Title:

Author(s):

\title{
FLOW CYTOMETRY-BASED DNA HYBRIDIZATION AND POLYMORPHISM ANALYSIS
}

\author{
RECEIVED \\ JUL 011998 \\ O.S.T.
}

Submitted to:

SPIE Conference Proceedings

San Jose, CA

$1-24-98$

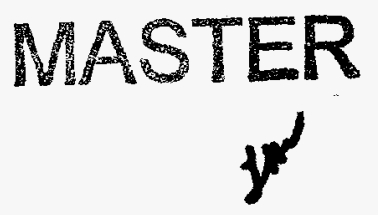

DISTAIBUTION OF THS DOCUMENT IS UNLMITED

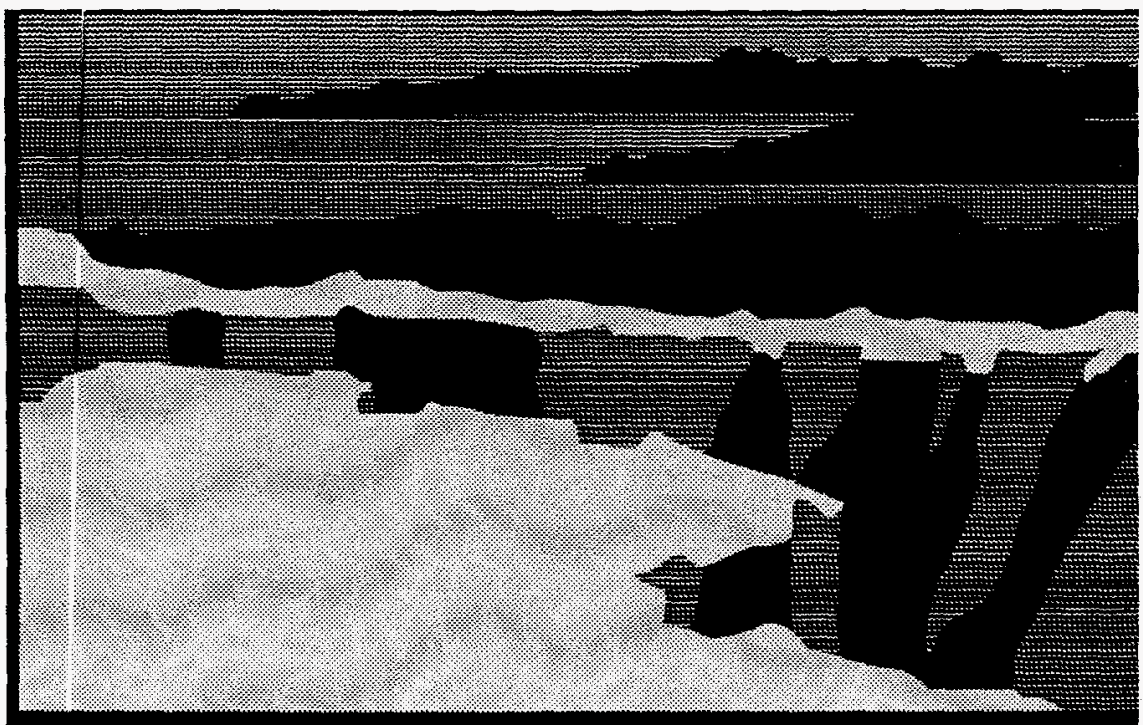

NATIONAL LABORATORY

Los Alamos National Laboratory, an affirmative action/equal opportunity employer, is operatea by the University or Caliornia ror the U.S. Lepartment or Energy under contract W-7405-ENG-36. By acceptance of this article, the publisher recognizes that the U.S. Government retains a nonexclusive, royalty-free license to publish or reproduce the published form of this contribution, or to allow others to do so, for U.S. Government purposes. The Los Alamos National Laboratory requests that the publisher identify this article as work performei under the auspices of the U.S. Department of Energy. The Los Alamos National Laboratory strongly supports academic freedom and a researcher's right to publish; as an institution, however, the Laboratory does not endorse the viewpoint of a publication or guarantee its technical correctness. 


\section{DISCLAIMER}

This report was prepared as an account of work sponsored by an agency of the United States Government. INeither the United States Government nor any agency thereof, nor any of their employees, makes any warranty, express or implied, or assumes any legal liability or responsibility for the accuracy, completeness, or usefulness of any information, apparatus, product, ot process disclosed, or represents that its use would not infringe privately owned rights. Reference herein to any specific commercial product, process, or service by trade name, trademark, manufacturer, or otherwise does not necessarily constitute or imply its endorsement, recommendation, or favoring by the United States Government or any agency thereof. The views and opinions of ituthors expressed herein do not necessarily state or reflect those of the United States Government or any agency thereof. 


\section{DISCLAIMER}

Portions of this document may be illegible electronic image products. Images are produced from the best available original document. 


\title{
Flow cytometry-based DNA hybridization and polymorphism analysis
}

\author{
Hong Cai ${ }^{a}$, Kristina Kommander ${ }^{b}$, P. Scott White, and John P. Nolan ${ }^{b}$ \\ ${ }^{a}$ Chemical Science and Technology Division and ${ }^{b}$ Life Sciences Division \\ Los Alamos Nátional Laboratory, Los Alamos, NM 87545
}

\begin{abstract}
Functional analysis of the human genome, including the quantification of differential gene expression and the identification of polymorphic sites and dise:se genes, is an important element of the Human Genome Project. Current methods of analysis are mainly gel-based as:iays that are not well-suited to rapid genome-scale analyses. To analyze DNA sequence on a large scale, robust and high throughput assays are needed. We are developing a suite of microsphere-based approaches employing fluorescence detection to screen and analyze genomic sequence. Our approaches include competitive DNA hybridization to measure DNA or RNA targets in unknown samples, and oligo ligation or extension assays to analyze single-nucleotide polymorphisms. Apart from the advantages of sensitivity, simplicity, and low sample consumption, these flow cytometric approaches have the potential for high throughput multiplexed analysis using multicolored microspheres and automited sample handling.
\end{abstract}

Keywords: DNA, hybridization, single nu:leotide polymorphism, flow cytometry, genome, oligo ligation, primer extension, PCR, fluorescence, microsphere

\section{INTRODUCTION}

As the Human Genome Project progresses rapidly toward completion of primary sequencing, it is recognized that the functional analysis of sequences is equally important to our understanding of the human genome. Such functional analyses, including the identification of genetic variation and disease-related genes, and the quantification of differential gene expression will provide important clut:s about human population evolution, the relation between genomic structure and function, as well as enable the developrnent of many diagnostic tools. To analyze sequences on a large scale, robust and high throughput assays are needed. Ho'vever, many current technologies for genomic analysis are gel electrophoresisbased and therefore not ideal for large scale analysis.

Flow cytometry is capable of sensitive and quantitative fluorescence measurements of individual particles without the need to separate free from particle-bound probe. Analysis rates are very high (hundreds to thousands of particles per second) and multiple fluorescence and light scatter signals can be detected simultaneously. These features make flow cytometry an extremely powerful analytical tool for the analysis of macromolecular assemblies (Nolan et al., these Proceedings). Here we describe a suite of microsphere-based flow cytometry methods for the detection and quantification of specific sequences, and the analysis of single nucleotide polymorphisms (SNPs).

The detection of specific nucleic acids in urknown samples is most often achieved via gel-based methods such as Northern or Southern blotting. These apprraches take advantage of hybridization, the pairing of complementary nucleic acid strands, to achieve highly specific detection. Hybridization can take place either in solution or with one of the nucleic acids immobilized on a surface. Hybridization in solution is often faster, but it is difficult to separate unhybridized single stranded nucleic acid from double stranded hybridized nucleic acid (Nelson, 1990). For this reason, most hybridization-based methods use immobilization of either target or probe molecules so that free unhybridized nucleic acids in solution can simply be washed away. Hybridization on nitrocellulose or nylon membranes is widely used in many laboratories, however membrane-based hybridization often results in high background signals due to the porous structure of these membranes (Hull, 1988). Microtiter plate- and microsphere-based assays can avoid this problem. While 96-well microtiter plates are popular for screening large numbers of samples (Zammatteo, 1997), microspheres offer the advantages of a large surface area with a well defined capacity, rapid binding kinetics and higher yield of hybridization. Flow cytometry has the ability to measure microsphere-associated fluorescence without any washing step, a feature that could allow strtamlined sample processing. We have adapted various nucleic acid hybridization protocols to microsphere-basid flow cytometry. We demonstrated the direct measurement of DNA hybridization, and extend this to the detection of specific sequences in unknown samples by competitive hybridization. The feasibility of this approach is demonstrated by detecting a chronic beryllium disease-associated (CBD-associated) gene target on PCR products amplified from genomic DNA (White et al., 1997). This general approach will be useful for a large range of sequence detection applications, including differential gene expression, bioagent detection and identification, and forensics. 
Single nucleotide polymorphisms represent the single largest class of sequence variation between individuals (Cooper, 1985 and 1993). These sites are present at high density in the genome and are highly conserved, making them powerful tools for mapping and diagnosing disease-related alleles. Thus as sequencing and mapping of the human genome is accomplished, detection and analysis of SNPs will be a major objective for genome research. The most straightforward approach to detect known SNPs might seem tis be direct sequencing, but the time and cost of direct sequencing on a large number of samples is prohibitive. Other methods include denaturing gradient gel electrophoresis (Sheffield, 1989), chemical or enzymatic cleavage (Cotton, 19813, Myers, 1985 and Youil, 1995), the analysis of heteroduplex and singlestranded DNA conformations (Glavac, 1995 and Orita, 1989), hybridization to oligonucleotide arrays (Hacia, 1996) and microtiter plate-based oligo ligation (Nickersc n, 1990). However, each of these approaches has its drawbacks, ranging from time-consuming gel electrophoresis step;, sequence-dependent optimization of reaction conditions, or high reagent consumption, factors which limit their application on a large scale. In this work, we describe a rapid and sensitive oligo ligation assay using flow cytometry to analyze base composition at SNP sites. This assay does not require separation of bound and free molecules or sequence-dependent optimization. Once optimized, it can be multiplexed to carry out the rapid analysis of a large number of samples irı one experiment.

In this report we demonstrate our ability to directly detect nucleic acid hybridization by flow cytometry, to use this capability to detect specific sequences in unkrıown samples by competitive hybridization, and to interrogate the base composition at specific sites using oligo ligation. Flow cytometry allows these analyses to be performed using smail reaction volumes and reagent amounts, with sensitivity which surpasses even other fluorescence-based methods. Further potentiating the flow cytometric approach is the possibility multicolor detection, which can allow multiplexed analysis of many sequences simultaneously to provide the high sample throughput required for genome scale analyses.

\section{MIATERIAL AND METHODS}

Oligonucleotides: The DNA oligonucleotides (see Table 1) were synthesized on an automated ABI DNA synthesizer using suggested protocols from Glen Research (Stetling, Virginia). The biotinylated and fluorescent-labeled oligomers were synthesized using biotin-phosphoramidites and fluorescein modifier purchased from Glen Research (Sterling, Virginia). The amine-modified oligomers were made using 5'-amino-modified C12 (Glen Research). The 5'-phosphate modified oligomers were synthesized using 5'-phosphate linker purchased from Perkin Elmer (Poster City, CA). All the synthesized oligonucleotides were purified by polyacrylamide gel electrophoresis and the concentrations of the purified oligonucleotides were measured by absorbance at $260 \mathrm{~nm}$ using an extinction coefficient of $33 \mu \mathrm{g} / \mathrm{ml}$ per $\mathrm{A}_{2} 60$ unit.

Table 1. Oligonucleotides used in this study

\begin{tabular}{ll}
\hline Oligonucleotides & Sequence: s of oligonucleotides \\
\hline HC1 (16-mer) & 5'-biotin-GTAAAACGACGGCCAG-3' \\
HC2 (16-mer) & 5'-fluorescein-CTGGCCGTGGTTTAC-3' \\
HC3 (18-mer) & 5'-biotin-CTGTCCGGCACTGCCCGC-3' \\
HC4 (18-mer) & 5'-fluorescein-GCGGGCAGTGCCGGACAG-3' \\
HC5 (18-mer) & 5'-CTGICCGGCACTGCCCGC-3' \\
HC6 (18-mer) & 5'-GCGC'GCAGTGCCGGACAG-3' \\
HC7 (20-mer) & 5'-amine-AAGGACATCCTGGAGGAGGA-3' \\
HC8 (20-mer) & 5'-amine-AAGGACATCCTGGAGGAGAA-3' \\
HC9 (20-mer) & 5'-amine-AAGGACATCCTGGAGGAGTA-3' \\
HC10 (20-mer) & 5'-amine-AAGGACATCCTGGAGGAGCA-3' \\
HC11 (44-mer) & 5'-CTGTCCGGCACTGCCCGCTCCTCCTCCAGGATGTCCTTC \\
HC12 (18-mer) & TGGCT-3' \\
\hline
\end{tabular}

Fluorescence detection by flow cytometer: Flow cytometric measurements of microsphere fluorescence were made on a Becton-Dickinson FACSCalibur (San Jose, CA). The samples were illuminated at $488 \mathrm{~nm}(15 \mathrm{~mW})$, and forward angle light scatter (FALS), 90 degree light scatter SSC), and fluorescence signals through a $530( \pm 30) \mathrm{nm}$ band-pass filter were acquired. Linear amplifiers were used for all measurements. Particles were gated on forward angle and 90 degree light scatter, and the mean fluorescence channel numbers were recorded.

DNA hybridization assay: The binding of the 5'-biotinylated oligonucleotide probe, $\mathrm{HC1}$ to $6.2 \mu \mathrm{m}$ streptavidin-coated polystyrene microsphere (Spherotch Inc., Libertyville, IL) was performed in TE buffer ( $100 \mathrm{mM}$ Tris- $\mathrm{HCl}, \mathrm{pH}, 8.0,0.5$ $\mathrm{mM}$ EDTA) by incubating the microspheres $\left(50 \mu \mathrm{l}, 1 \mathrm{X}^{7} 0^{7}\right.$ beads $\left./ \mathrm{ml}\right)$ and oligonucleotides $\mathrm{HCl}(50 \mu \mathrm{l}, 10 \mathrm{nM})$ at room 
temperature for 2 hours. The hybridization of fluorescent complementary strand (fluorescent reporter), HC2, was carried out by incubating $\mathrm{HC} 2(10 \mu \mathrm{l})$ at different $\mathrm{C}$ incentrations ranging from $5-500 \mathrm{nM}$ with the $\mathrm{HCl}$-bead $(10 \mu 1)$ at room temperature for 2 hours. The reaction mix was then diluted 100 -fold with TE/BSA ( $50 \mathrm{mM}$ Tris- $\mathrm{HCl}, \mathrm{pH}, 8.0,0.5 \mathrm{mM}$ EDTA, $0.5 \%(w / v)$ bovine serum albumin, ESA) and the microsphere fluorescence was measured by flow cytometry.

Competitive DNA hybridization assay: The linding of the biotinylated probe, $\mathrm{HC} 3(2.4 \mathrm{nM})$ to the streptavidin-coated microsphere was performed as described above. The double-stranded duplex HC5/HC6 was formed by hybridizing equal amounts of $\mathrm{HC} 5$ to $\mathrm{HC} 6$ in TE buffer at 95 " $\mathrm{C}$ for 2 minutes and gradually cooling to room temperature over a period of $30 \mathrm{~min}$. The competitive hybridization of fluorescent reporter oligomer, $\mathrm{HC} 4$ and $\mathrm{HC} 5 / \mathrm{HC} 6$ duplex at different concentrations was carried out by heating the reaction mix $(20 \mu \mathrm{l}, 1.2 \mathrm{nM} \mathrm{HC} 4,0-250 \mathrm{nM}$ duplex HC5/HC6 in TE) at $95^{\circ} \mathrm{C}$ for 2 minutes and gradually cooling to room temperature over a period of 40 minutes. A $10 \mu$ aliquot of reaction solution at each concentration containing $\mathrm{HC} 4$ and $\mathrm{HC} 5 / \mathrm{HC} 6$ was transferred to a new microcentrifuge tube and mixed with $10 \mu \mathrm{l} \mathrm{HC} 3 /$ bead. The reaction mix was incubated at room temperature for 1 hour and diluted 100 -fold with TE/BSA for fluorescence measurement. The fluorescence on the bead was plotted as a function of HC5/HC6 duplex concentration (Fig. 2b). The 300 bp PCR fragment containing HC5/HC6 duplex sequences were made by a typical PCR protocol (White et al., in press). The DNA competitive hybridization assay on crude PCR fragments was performed following the same procedure described for duplex HC5/HC6. In this case, the concentration of the PCR DNA was determined by a separate experiment where the PCR fragment was separated on a $1 \%$ agarose gel, stained with ethidium bromide, and the concentration was calculated based on inten sity measurements by a densitometer on both PCR fragments and DNA standards.

Oligo ligation assay: To attach oligomers tis microspheres covalently, the 5 '-amine-modified probes were reacted with the carboxylated microsphere (5.4 $\mu \mathrm{m}$, Polysciences, Inc., Warrington, PA) in the presence of excess 1,ethyl-3-(3dimethylaminopropyl)carbodiimide hydrochloride (EDC, PIERCE, Rockford, IL) to form a stable amide bond. The reaction was performed in $0.1 \mathrm{M}$ MES buffer (2-[N-morpholino]ethanesulfonic acid, $\mathrm{pH}, 4.8$ ). The conjugated bead mix was washed three times with TE buffer and the bead concentration was determined using a Coulter counter. In this case, four oligonucleotides with different 3' terminal base (HC7 with G, HC8 with A, HC9 with T and HC10 with C) were attached to the carboxylated microspheres and unreacted oligonucleotide was washed away. The final concentration of the oligo-conjugated bead was $1 \times 10^{7}$ beads/ml. A ligation mix containing the complementary sequences (HC11, containing the target sequence), the fluorescent adapter ( $\mathrm{HC12}$ ) and DNA ligase (Thermoligase from Epicentre, Madison, WI or T4 DNA ligase from USB, Cleveland, $\mathrm{OH}$ ) was: added to each oligo-conjugated bead. The ligation reaction was carried out in the reaction buffer as suggested by the manıfacture and the reaction conditions are indicated in Fig. $3 \mathrm{~b}$. After the reaction, the reaction mix was diluted 100-fold with TE/BSA for fluorescence measurement by flow cytometry. Under these conditions, the microsphere conjugate 1 with $\mathrm{HC7}$ showed a 7-fold higher fluorescence compared to other probed microspheres, indicating that $\mathrm{HCl} 1$ sequence has a $\mathrm{C}$ base at the target sites (Fig. 3b).

\section{RESULTS AND DISCUSSION}

To obtain the full value of the human genorne sequence, routine methods for the rapid and sensitive detection and analysis of specific sequences in samples from many individuals will be needed. Current methods are not suitable for such large scale analysis. To address this need, we are developing a series of analyses based on flow cytometry including sequence detection by hybridization and sequence analysis by oligo ligation.

Hybridization assay: As an initial step to cleveloping hybridization-based assays using flow cytometry, we sought to characterize the features of oligonucleotide hybridization of microspheres. As depicted in Figure 1a, a biotinylated oligomer probe ( $\mathrm{HCl}$ ) was immobilized onto a streptavidin-coated microsphere, a fluorescent complimentary strand (HC2) was allowed to anneal, and the hybridization process was monitored as an increase in microsphere fluorescence as measured by flow cytometry. The kinetics of oligomer hybridization on the microsphere depends on the rate of binding of $\mathrm{HC} 2$ to $\mathrm{HCl}$ (on rate) and the rate of dissociation of the hybridized oligonucleotide from the immobilized DNA (off rate). As shown in Fig. 1b, hybridization of $\mathrm{HC} 2$ to $\mathrm{HC} 1$ is a concentration-dependent process: as $\mathrm{HC} 2$ concentration increases, the fluorescence of the microsphere first increases linearly and gradually reaches a plateau, suggesting the saturation of available hybridization sites in the bead. Hybridization in the presence of excess calf thymus DNA was similarly efficient (data not presented), indicating the hybridization is sequence-specific. The off rate of the hybridized oligomer, initiated by the addition of excess unlabeled competitor, is very slow (Cai et al., 1997, Nilsson et al., 1995), as would be expected for stable duplex DNA. Thus, using flow cytometry, it is possible to detect sub-nanomolar levels of hybridized DNA without separation steps (see later.discussions) whereas other nonradiation alternatives such as surface plasmon resonance (SPR)-based biosensol, often require $\mu \mathrm{M}$ level of DNA (Nilsson et al., 1995). 
(a)

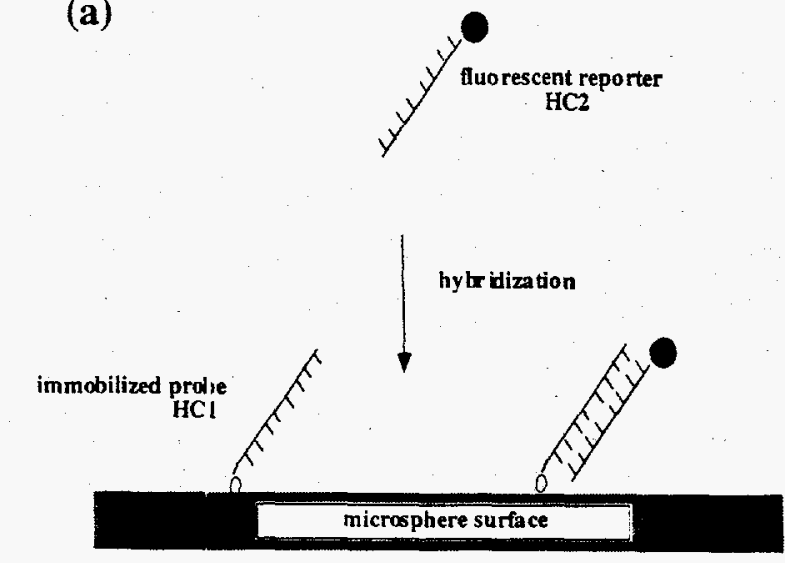

(b)

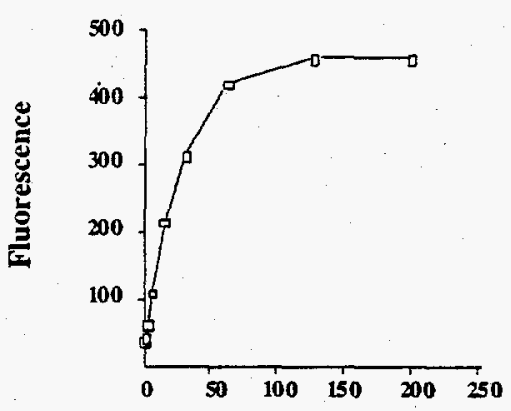

[Fluorescent reporter] (nM)

Fig. 1. Detection of DNA hybridization by flow cytometry. (a) Schematic illustration of DNA hybridization on the microsphere. (b) The experimental data of the oligonucleotide hybridization detected by fluorescence-based flow cytometry. The fluorescence signal on $6.2 \mu \mathrm{m}$ streptavid n-coated microspheres is plotted in arbitrary units. See Materials and Methods for details.

Competitive DNA hybridization assay: To icentify a particular gene target in a genome or library, different versions of hybridization-based southern blot (DNA-DNA interaction) or northern blot (DNA-RNA interaction) are widely used. All these assays require a separation of unbound probes; from the bound species. To detect the presence of a specific sequence in a complex sample, we exploited the ability of llow cytometry to make sensitive measurements of hybridization to develop a competitive hybridization assay (Fig. 2a).

In this scheme, an oligo probe containing the target sequence is immobilized on the microsphere, and its complement is fluorescently labeled. The fluorescent oligo (fluorescent reporter) is then incubated with the unknown sample. If the target sequence is present, the fluorescent reporter will bind, depleting this oligo from solution, and reducing the degree of hybridization upon subsequent addition of the probe bearing microspheres. In our example, a synthetic oligonucleotide duplex, HC5/HC6 was used to compete with the fluorescenated reporter (HC4) for annealing to the probe sequence. As shown in Fig. 2b, the fluorescence on the misrosphere decreases as the concentration of target HC5/HC6 increases. A concentration of $0.5 \mathrm{nM}$ target DNA was dettcted as a 20\% decrease of fluorescence signal. The same experiment was carried out on a crude PCR reaction containing 300 bp DNA with the target sequence. Efficient competition was observed even in this more complex mixture (Fig. 3c), resulting in an assay with sensitivity comparable to that obtained with short oligos as the target sequence. These results demonstrate that competitive hybridization using flow cytometry allows the rapid identification and quantification of a specific target in a crude PCR sample without separation steps. Because flow cytometrybased fluorescence detection is sensitive and rapid, it has the potential to be used as an alternative to Southern and Northern blots and the RNase protection assays to screen and analyze DNA, cDNA, or mRNA targets. 
(a)
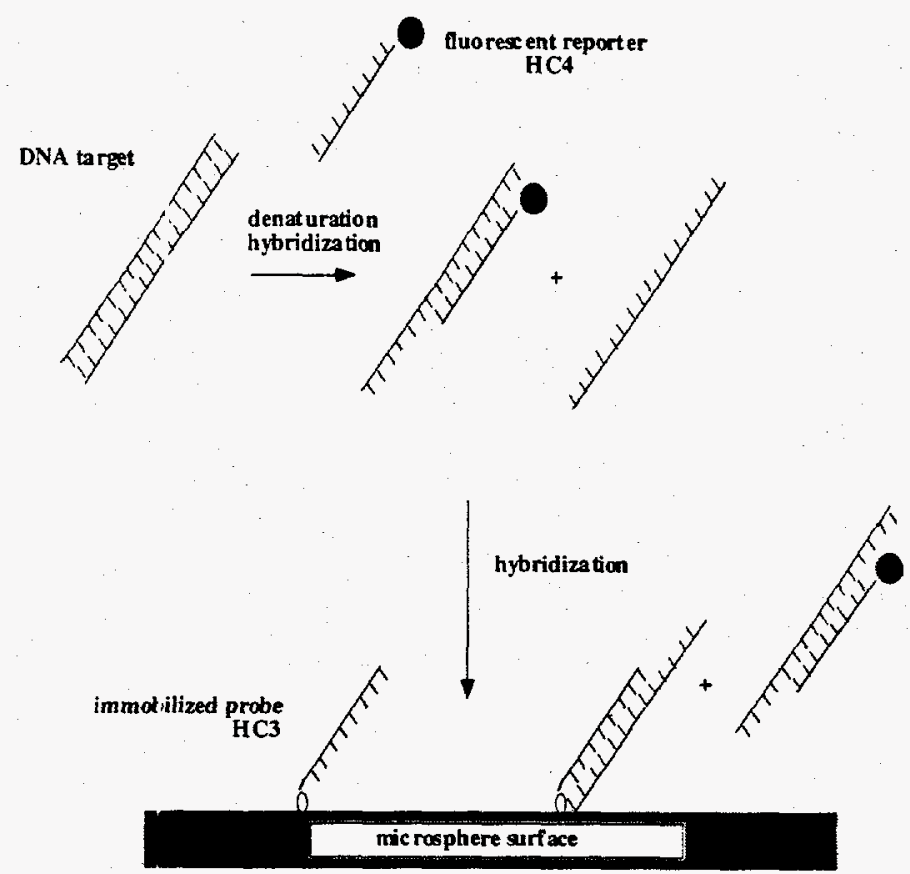

(b)

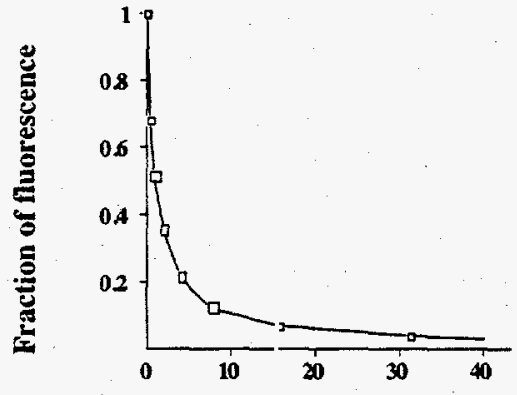

[Oligonucleotide target](nM) (c)

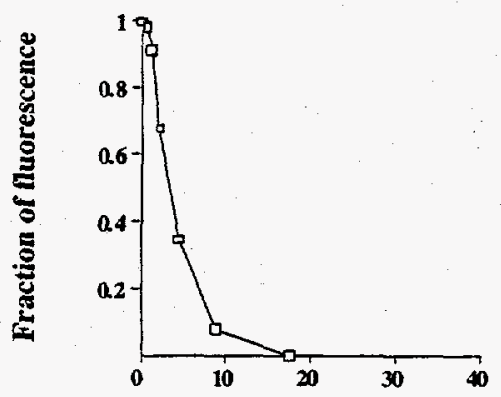

[Target] (nM)

Fig. 2. Detection of target DNA by compititive hybridization using flow cytometry. (a) Schematic illustration of competitive hybridization. (b) Competitive hybridization on synthetic oligonucleotide model system. (c) Detection and quantification of target DNA sequence in a :rude PCR sample. The experiment was carried out as described in Materials and Methods.

Oligo ligation assay: It has been shown that single base substitutions are the most frequent forms of DNA sequence variation in the human genome (Cooper, 1985 and 1593). Identification of these single nucleotide polymorphisms (SNPs) is important to our understanding of genetic variation, population structure, and to studies of disease genes. As SNP analysis becomes increasingly important to the human genome project, a robust and high throughput method is needed to scan and analyze a large number of DNA samples for large numbers of targets. Taking advantage of flow cytometry, we are aiming for a simple, rapid SNP analysis assay. SNPs can be detected and quantified oligo ligation using microsphere-based flow cytometry. For each SNP, four probes, each with a different terminus, are synthesized and immobilized on microspheres. The hybridization of the probe to a target is carried out in the presence of a fluorescent reporter oligonucleotide that binds adjacent to the SNP site simultaneously. The porbe with the correct termini and the adjacent reporter are then covalently jointed by DNA ligase, resulting in a fluorescence sigual under denaturing conditions. To test the feasibility of the ligation assay, a simple oligonucleotide model system was used. As illustrated in Fig. 3a. oligonucleotide probes ( $\mathrm{HC}$, HC8, HC9, $\mathrm{HCl0}$ ), 
each with a different terminal nucleotide, were covalently attached onto microspheres as described in Materials and Methods. A fluorescent reporter oligomer, $\mathrm{HCl} 2$ was $\mathrm{cc}$-assembled to the target $\mathrm{DNA}(\mathrm{HC} 11)$ along with probes, and subsequently ligated to the correct probes by DNA ligase. Because the fluorescent reporter anneals to targets regardless of the composition of the probe terminal nucleotide, a denaturing step (heating at $95^{\circ} \mathrm{C}$ and adding excess competitor DNA) was introduced to allow discrimination between hybridized and ligated probe. The fluorescence on the microsphere was then measured by flow cytometry for each probe and the sequence at the SNP site was determined by the fluorescence on the appropriate microsphere (Fig. 3b). This experiment was performed with two different DNA ligases, T4 DNA ligase at $14{ }^{\circ} \mathrm{C}$, and a thermostable DNA ligase at $50^{\circ} \mathrm{C}$. The microsphere immobilized with $\mathrm{HC} 7$ gave the highest fluorescence compared to the microspheres with other probes indicating a $G$ residue at SNP site. Note that both ligases resulted in the same 6-7 fold discrimination of correct from incorrect sequence at SNP site, suggesting that hybridization of probes were not as specific against the SNP under $t$ these reaction conditions as would be desired. Greater discrimination may be achieved by ligation at higher temperatures using Thermoligase, shorter primer length or possibly an artificial mismatched primer design (Guo, 1997).

(a)
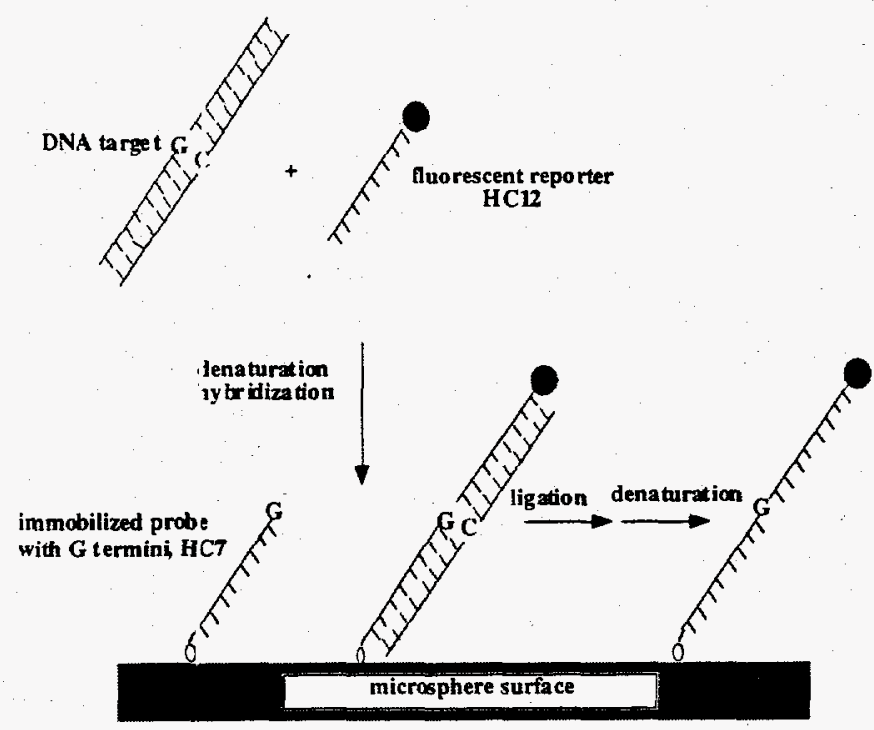

(b)

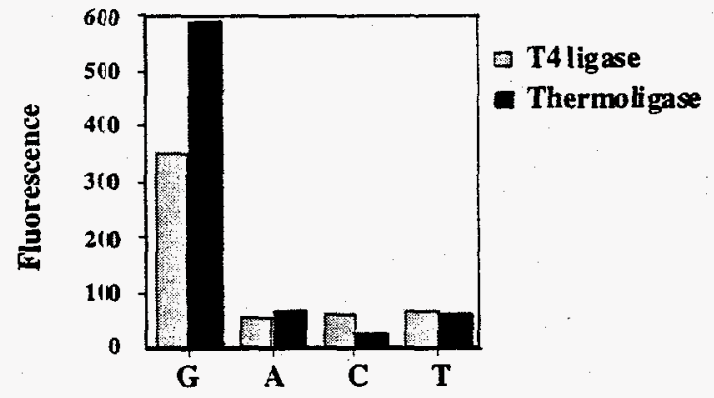

Probes with different termini

Fig. 3. Analysis of SNPs by oligo ligation assay using microsphere-based flow cytometry. (a) Schematic illustration of ligation assay. (b) Ligation assay on the synthetic model target. The ligation assay was performed using two types of ligases on the synthetic target, $\mathrm{HC} 11$ oligonucleotide as described in the materials and methods.

We are also developing a minisequencing approach to SNP analysis using DNA polymerase and fluorescent dideoxynucleotides. For both the oligo liga:ion method and the minisequencing method, flow cytometry offers sensitive 
fluorescence detection without the need to seprarate free from bound label. Furthermore, for all of the analyses presented here (sequence detection by hybridization ancl SNP analysis), multicolor detection by flow cytometry offers the potential for the multiplexed analysis of many sequences simultaneously using sets of dyed fluorescent microspheres. In this approach, distinct microsphere populations are identified by the intensity one or more fluorescent dyes, and each population bears a unique sequence. Separate emission wavelengths are used to identify microspheres and make the measurements.

\section{SUMMARY}

In this report, we present a new suite of microsphere-based approaches to carry out sequences analysis, such as identification of target genes and single-nucleotide polymorphisms using flow cytometry technology. We have developed a rapid hybridization-based assay for gene identification and quantification, and the feasibility of this assay has been demonstrated on PCR fragments amplified from genomic DNA containing a CBD-associated gene target . We also developed an oligo ligation assay for single-nucleotide polymorphism analysis and have demonstrated proof-of-principle on a synthetic target. Once optimized, we believe these approaches will be developed into rapid, automated multiplexed and high throughput assays for large scale sequence analyses needed for the next phase of Human Genome Project.

\section{ACKNOWLEDGMENTS}

We thank Sue Thompson for the synthesis of all DNA oligomers and Owatha $L$. Tatum for providing us with PCR DNA fragments used in this work. We also thank Dr. Susan Riley, Dr. Jim Jett and Dr. Babetta Marrone for their help and discussions. This work was supported by the NIH (RR01315), the Department of Energy (Los Alamos Center for Human Genome Studies, F159) and Los Alamos National Laboratory (LDRD XAHJ).

\section{REFERENCES}

Cai, H., Kommander, K., White, S., Keller, R. A. and Nolan, J. P. Manuscript in preparation.

Cooper, D. N., Smith, B. A., Cooke, H. J., Hiemann, S. and Schmidtke, J. (1985) Hum. Genet., 69, 201-5

Cooper, D. N. and Krawczak, M. (1993) Human Gene Mutation. Bios Scientific, Oxford, UK

Cotton, R.G., Rodrigues, N. R. and Campbell, R. D. (1988) Proc. Natl. Acad. Sci. USA, 85, 4397-401

Glavac, D. and Dean, M. (1995) Hum. Mutat., 6, 281-7

Guo, Z., Liu, Q and Smith, L. (1997) Natu'e Biotechnology, 15, 331-5

Hull, R., and Al-Hakim, A. (1988) Trends Biotechnol. 6, 213-218

Myers, R. M., Larin, Z. and Maniatis (198:i) Science, 230, 1242-6

Nelson N. C., and Kacian, D. L. (1990) Clin. Chem. Acta, 194, 73-90

Nickerson DA, Kaiser, R., Lappin, S., Stewart, J., Hood, L. and Landgren, U. (1990) Proc Natl Acad Sci, 87:8923-8927.

Nilsson, P., Persson, B., Uhlen, M., and Ny'gren, P.-Å. (1995) Analytical Biochemistry 224, 400-408.

Sheffield, V. C., Cox, D. R., Lerman, L. S. and Myers, R. M. (1989) Proc. Natl. Acad. Sci. USA, 86, 232-6

Youil, R., Kemper, B. W. and Cotton, R. (J. (1995)Proc. Natl. Acad. Sci. USA, 92, $87-91$

White, P. S., Petrovic, M., Tatum, O. L., Lehnert, N., S-Nair Usha, Wang, Z., Deaven, L. L. and Marrone, B. (1997) DOE

Human Genome Program Contractor-Grantee Workshop VI, 66-66

White, P.S., Tatum, O. L., Tegelstrom, H. and Densmore, L. D. (in press) In Molecular Genetic Analysis of Populations: A Practical Approach, 2nd ed. (A. R. Hoelzel, ed), IRL Press, Oxford

Zammatteo, N., Alexandre, I., Ernest, I., L2, L., Brancart, F. and Remacle, J. (1997) Anal. Biochem., 253, 180-89 